\title{
Hybrid GMSA for Optimal Placement and Sizing of Distributed Generation and Shunt Capacitors
}

\author{
Emad A. Mohamed ${ }^{1,2, *}$, Al-Attar Ali Mohamed ${ }^{2}$ and Yasunori Mitani ${ }^{1}$ \\ ${ }^{1}$ Department of Electrical and Electronics Engineering, Kyushu Institute of Technology, 1-1 Sensuicho, Tobata-ku, Kitakyushu-shi, \\ Fukuoka 804-8550, Japan \\ ${ }^{2}$ Department of Electrical Engineering, Faculty of Engineering, Aswan University, Aswan 81542, Egypt
}

Received 16 December 2017; Accepted 20 January 2018

\begin{abstract}
This work presents a hybrid approach based on the genetic algorithm (GA) and moth swarm algorithm (MSA), namely genetic moth swarm algorithm (GMSA). Minimizing the electrical power loss in radial distribution systems (RDN) within the framework of system operation and under system constraints is the main objective of this study. In GMSA, the global search ability has been regulated by the incorporation of GA operations by the adaptive mutation operator on the reconnaissance phase using genetic pathfinder moths. In addition, the selection of artificial light sources has been expanded over the swarm. The representation of individuals within the three phases of MSA has been modified in term of quality and ratio. Elite individuals have been used to play different roles in order to reduce the design space and thus increase the exploitation ability. GMSA and other optimization methods have been carried out on the IEEE 33 and 69-bus power systems. The reduction of power loss and total system cost in addition to the improvement of the minimum bus voltage are simulated for the competitive algorithms under several power system constraints and conditions. The computational results proved the superiority of the GMSA compared with other techniques.
\end{abstract}

Keywords: Radial distribution system, optimal capacitor and DG location, loss reduction, Genetic-Moth Swarm Algorithm

\section{Introduction}

Most of the electrical distribution networks feed inductive loads at low voltage levels. This effect leads to higher currents and power losses accompanied by voltage drop whereas about $13 \%$ of the total power generation has been considered as line losses [1]. Therefore, these losses must be diminished to improve the power system stability and reliability, power factor and voltage profile. Connecting distributed generation resources or/and shunt capacitors is considered as one of the basic methods which have been used in distribution systems to solve such problems [2, 3].

Shunt capacitors are considered as the best-known technique, which used in RDN for reactive power compensation. Different heuristic techniques have been developed to solve the optimal power flow problems using capacitors, as commonly used for reactive power compensation in dynamic and static optimization modes [48]. However, the random locating of capacitors can cause more voltage drop and higher power losses. Moreover, the capacitor allocation problem has a combinatorial nature because capacitor locations and sizes are discrete variables $[4,5]$. On the other hand, the utilizing of DG resources and inexpensive renewable sources in electrical networks with the development of technologies are increasing. This development provides many advantages for the electrical network such as increasing reliability, active and reactive power losses reduction and improving voltage profile.

\footnotetext{
*E-mail address: 45955060@mail.kyutech.com

ISSN: 1791-2377 @ 2018 Eastern Macedonia and Thrace Institute of Technology. All rights reserved.

doi:10.25103/iestr.111.07
}

However, these merits occur depend on the optimal placing and sizing of DG sources [9]. Therefore, several optimization algorithms have been proposed in recent years to solve the optimal of DG resources and shunt capacitor placement and sizing problems in radial and ring distribution systems for maximizing their benefits such as Flower pollination algorithm (FPA) [9], particle swarm optimization (PSO) $[10,11]$, discrete particle swarm optimization (DPSO) [12], genetic algorithm (GA) [13], teaching-learning-based optimization (TLBO) [14], artificial bee colony (ABC) [15], cuckoo search algorithm (CSA) [16], gravitational search algorithm (GSA) [17], modified monkey search (MMS) [18], whale optimization algorithm (WOA) [19], improved harmony algorithm (IHA) [20], moth swarm algorithm (MSA) [21], direct search algorithm (DSA) [22], differential evolution algorithm (DEA) [23], simulated annealing (SA) [24], plant growth simulation algorithm (PGSA) [25], fuzzy reasoning (FRB) [26], improved binary particle swarm optimization (IBPSO) [27], and fuzzy-GA [28] have been presented to deal with the problem of the DG and capacitor allocation. However, some of these algorithms are not highly effective as the power losses still have high values. Other algorithms appear to be effective, but they may not achieve the optimal cost value. GMSA is developed based on the incorporation of GA operations with adaptive mutation operator on the reconnaissance phase using genetic pathfinder moths and the expanding of artificial light sources over the swarm.

In this paper, GMSA and four heuristic search algorithms are presented to minimize the system power losses, decrease the total cost and maintain the voltage profile for various electrical distribution systems. It is tested 
on multiple IEEE standard distribution systems i.e., (33and 69-bus). In addition, the obtained results from the proposed approach are compared with those obtained from other algorithms to confirm its superiority. The article is organized as follows; section. 2 provides the objective function formulation. GMSA algorithm is represented in section 3. In section.4, the implementing of GMSA pseudo code for solving the DG and capacitor allocation problem has been presented. Section 5 shows the numerical results of the proposed technique applied on multiple IEEE standard systems. The last section concludes the results and advantages of the proposed method.

\section{Problem Formulation}

\subsection{Load flow calculation}

The modern algorithm called backward/forward sweep [29] is used in this work to analyse the power flow in the tested IEEE distribution systems. The active power flow $\left(P_{k}+1\right)$ and reactive power flow $\left(Q_{k}+1\right)$ in RDN are calculated by (1) and (2) derived from single-line diagram as shown in Fig. 1.

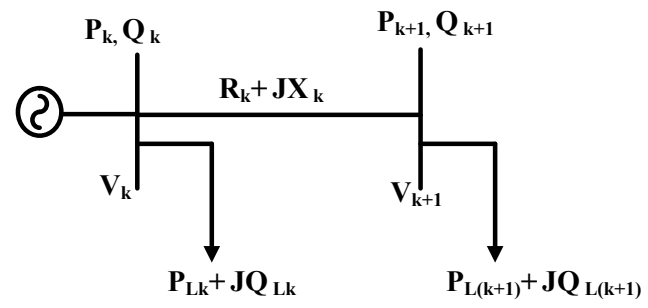

Fig. 1. Simple radial distribution system

$$
\begin{aligned}
& P_{k+1}=P_{k}-P_{L(k+1)}-R_{k} \frac{P_{k}^{2}+Q_{k}^{2}}{V_{k}^{2}} \\
& Q_{k+1}=Q_{k}-Q_{L(k+1)}-X_{k} \frac{P_{k}^{2}+Q_{k}^{2}}{V_{k}^{2}}
\end{aligned}
$$

where $\mathrm{k}$ is the sending end and $\mathrm{k}+1$ is the receiving end. Voltages of a transmission line and real power losses in the line can be calculated from (3) and (4) respectively:

$$
\begin{aligned}
& V_{k+1}^{2}=V_{k}^{2}-2\left(R_{k} \cdot P_{k}+X_{k} \cdot Q_{k}\right)+\left(R_{k}^{2}+X_{k}^{2}\right) \cdot \frac{\left(P_{k}^{2}+Q_{k}^{2}\right)}{V_{k}^{2}} \\
& P_{l o s s(k, k+1)}=R_{k} * \frac{\left(P_{k}^{2}+Q_{k}^{2}\right)}{V_{k}^{2}}
\end{aligned}
$$

The total system loss is calculated by summing all line losses in the system as shown in (5):

$$
P_{\text {Tloss }}=\sum_{k=1}^{n-1} P_{l o s s(k, k+1)}
$$

\subsection{Objective Functions}

The main aim of the objective function of the optimal DG and capacitor placement problem is to minimize the total cost per year by reducing the real power losses and the cost of installing capacitors subjected to voltage and reactive power limits. Hence, the multi-objective functions have been performed by using the following mathematical statement:

Minimize

$$
f=\min \left(\mathrm{P}_{\mathrm{T}} \text { loss }\right)
$$

\subsection{Constraint Conditions}

The objective function is subjected to the following constraints:

\subsubsection{Active and reactive power balance}

The following relation could be established for maintaining the balance between generation and consumption.

$P_{s y s}+P_{D G}=P_{d}+P_{\text {Tloss }}$

$Q_{s y s}+Q_{D G}+Q_{c a p}=Q_{d}+Q_{\text {Tloss }}$

The constraints of DG capacities are as follows:

$P_{D G}^{\min } \leq P_{D G}^{k} \leq P_{D G}^{\max }$

$Q_{D G}^{\min } \leq Q_{D G}^{k} \leq Q_{D G}^{\max }$

\subsubsection{Voltage constrain $t$}

The bus voltage magnitude of each bus must be maintained within the following range:

$V_{\min } \leq\left|V_{k}\right| \leq V_{\max }$

where $V_{\max }$ and $V_{\min }$ are the maximum and minimum values of bus $(k)$ voltages. The lower and upper values are taken as 0.9 and $1.05 \mathrm{Pu}$, respectively.

\subsubsection{Total reactive power constraint}

The total injected reactive power is limited by (12).

$Q_{f c} \leq \sum_{k=1}^{n} Q_{L k}$

\section{The proposed genetic moth swarm algorithm}

\subsection{Genetic algorithms}

Genetic algorithms (GAs), initially introduced by John Holland as the main global optimization technique. These algorithms have been applied successfully to solve a large number of problems in different real world fields by simulating the natural evolution systems. The recombination operation produces offspring that carry a combination of genetic material information from each parent where crossover operations are applied to exchange the chromosomes. The natural selection determines the evolution where the survival of the fittest. Therefore, a suitable selection strategy is then used determine the solutions that survive to the next generation based on their fitness values. The mutation operation is the main genetic operator that can achieved some diversity in the population.

\subsection{Moth Swarm Algorithm}

The moth swarm algorithm has been presented in 2016 by Al-Attar et. al [30]. It is inspired from the orientation of moths towards moonlight. The available solution of any optimization problem using MSA is performed by the light source position, and its fitness is the luminescence intensity of the light source. Furthermore, the proposed method consists of three main groups, the first one is called pathfinders which are considered a small group of moths 
over the available space of the optimization. The main target of this group is to guide the locomotion of the main swarm by discriminating the best positions as light sources. Prospectors group is the second one which has a tendency to expatiate in a non-uniform spiral path within the section of the light sources determined by the pathfinders. The last one is the onlookers, this group of moths move directly to the global solution which has been acquired by the prospectors.

\subsection{The genetic moth swarm algorithm}

The proposed hybrid based algorithm aims to integrate advantages of the well-known GA in term of sharing information and global search ability to find the optimal value of a given function using the following steps:

\subsubsection{Initialization}

Initially, the positions of moths are randomly created for dimensional (d) and population number (n) as seen in (13).

$$
\begin{aligned}
& x_{i j}=\operatorname{rand}[0,1] .\left(x_{j}^{\max }-x_{j}^{\min }\right)+x_{j}^{\min } \forall i \in\{1,2, \ldots, n\}, \\
& j \in\{1,2, \ldots, d\}
\end{aligned}
$$

where, $x_{j}^{\max }$ and $x_{j}^{\min }$ are the upper and lower limits, respectively. Afterwards, the type of each moth is selected based on the determined fitness. Consequently, the worst moths is selected as pathfinders that modified to act genetically in the following reconnaissance phase. In the next two phases, the best individuals of the swarm are regarded as prospectors and onlookers, respectively, according to their fitness. In addition, each moth in the modified algorithm has its own light source which is available to share with others in the swarm.

\subsubsection{Genetic Reconnaissance phase}

The moths may be concentrated in the regions which seem to be a good performance. Therefore, the swarm quality for reconnaissance may be decreased during processing the optimization and this process may lead to a stagnation case. To avoid the early convergence and enhance the solution diversity, a part of the swarm is compelled to determine the less congested area. The pathfinder moths that perform this role are manipulated to evolve by the genetic operators, with size of $\left(n_{p}=f \operatorname{loor}(n / 2)\right)$ selected from the worstperforming individuals in the swarm. The crossover and mutation operators of GA are applied on all moths in the swarm to improve the pathfinder group. Therefore, after the sorting of the population, the first half of the individuals that have better luminescence intensity values are regarded as candidate parents (elite individuals). The size of the elite individuals can be simply calculated using $n_{e}=n-n_{p}$.

The probability distribution function (pdf) is used to select parents, which is increased as the fitness of the individual be greater. Therefore, two of moths from the elite individuals are randomly selected as parents for one pathfinder moth. In order to perform the possible mating, a single crossover point is identified on both parents' vectors at random. The elite individuals are then divided at this point to exchange their tails thereby give birth to the new child pathfinder $\left(x_{p}\right)$. This ensures that the best candidates (local optima) are copying into the next generation. After the reproduction operation, a mutation operator based on normal distribution is applied to these offspring in order to increase their diversity and increase the ability to jump out of suboptimal/local solutions. For exploitation purpose, an adaptive mutation rate $\left(m_{\text {rate }}\right)$ is proposed to decrease through all iterations $\mathrm{T}$ as follows:

$m_{\text {rate }}=0.05 .(1-t / T)$

In order to achieve the completed trail solution, each pathfinder solution (host vector) updates its position through the crossover operations by incorporated the mutated variables of the sub-trail vector (low degree of dispersal) into the corresponding variables of host vector. The completed trail/mixed solution $\mathrm{V}_{\mathrm{pj}}$, may be described as:

$$
V_{p j}^{t}=\left\{\begin{array}{lll}
v_{p j}^{t} & \text { if } & j \in c_{p} \\
x_{p j}^{t} & \text { if } & j \notin c_{p}
\end{array}\right.
$$

The fitness value of the genetic pathfinder solution, $\mathrm{f}\left(\mathrm{x}_{\mathrm{p}}^{\mathrm{t}+1}\right)$ are determined after finishing the last procedure. The structure of worst half of the old population is then redesigned by comparing the fitness of these offspring with that of their previous positions $f\left(x_{p}^{t}\right)$. The suitable solutions that have the highest luminescence intensity are chosen to retain for the next generation, which is used for minimization problems as follows:

$$
\overrightarrow{x_{p}^{t+1}}=\left\{\begin{array}{lll}
\overrightarrow{x_{p}^{t}} & \text { if } & f\left(\overrightarrow{x_{p}^{t+1}}\right) \geq f\left(\overrightarrow{x_{p}^{t}}\right) \\
\overrightarrow{v_{p}^{t}} & \text { if } & f\left(\overrightarrow{x_{p}^{t+1}}\right)<f\left(\overrightarrow{x_{p}^{t}}\right)
\end{array}\right.
$$

Finally in this phase, the light sources are elected from among the combined population (survivors of the previous equation and their parents) to continue as guidance of the next phases. Therefore, the moths are changed dynamically in the GMSA model where any pathfinder moth uplifts to become prospector or onlooker moth if it discovers a solution with luminescence more than the existing light sources. That means the new lighting sources will be presented at the end of this stage. The probability $P_{i}$ of selecting the $i$ th moth as a light source is proportional to the corresponding fitness, which can be calculated as follows:

$$
p_{i}=\frac{f\left(x_{i}\right)}{\sum_{i=1}^{n} f\left(x_{i}\right)} \quad \forall i \in\{1,2, \ldots, n\}
$$

\subsubsection{Transverse orientation}

Individuals that have been selected as elites or parents have another role at this stage as prospectors. The number of these moths $n_{f}$ is proposed to decrease with time progress as:

$n_{f}=\operatorname{round}\left(\left(n-n_{p}\right) \times\left(1-\frac{t}{T}\right)\right)$

After the pathfinders have finished their search, the information about luminescence intensity is shared with prospectors, which attempt to update its positions in order to discover new light sources. Each prospector moth $x_{j}$ is soared into the logarithmic spiral path as shown in Fig. 2(a) to make a deep search around the corresponding artificial 
light source $x_{i}$, which is chosen on the basis of the probability $P_{i}$ using (18). The new position of $j$ th prospector moth, can be expressed mathematically as follows:

$$
\begin{aligned}
& x_{j}^{t+1}=\left|x_{j}^{t}-x_{i}^{t}\right| \cdot e^{\theta} \cdot \cos 2 \pi \theta+x_{i}^{t} \quad \forall \quad j \in\left\{1,2, \ldots, n_{f}\right\} \\
& ; \forall i \in\{1,2, \ldots, n\}
\end{aligned}
$$

where, $\theta \in[r, 1]$ is a random number to define the spiral shape and $r=-1-t / T$. The GMSA is dealing with each variable the previous formula as an integrated unit. At the end of this stage, only moonlight is updated. It should be noted that all moths in the modified swarm cooperate to discover new sources of light, which increases the area of selection and prevents from falling into local solutions and thus increases the efficiency of the proposed algorithm.

\subsubsection{Celestial navigation}

The diminishing of the number of prospectors during the optimization process increases the onlookers number $\left(\mathrm{n}_{\mathrm{o}}=n_{e}-\mathrm{n}_{\mathrm{f}}\right)$. This may lead to an increase in the speed of the convergence rate of GMSA towards the global solution. The onlookers are the moths that have the lowest luminescent sources in the parent group. Their main aim for traveling directly to the moon, which is the most shining solution Fig. 2(b). In the GMSA, the onlookers are forced to search for the hot spots of the prospectors effectively. These onlookers are divided into the two following parts:

The first part, with the size of $n_{G}=\operatorname{round}\left(n_{o} / 2\right)$, walks according to Gaussian distributions. The new onlooker moth in this sub-group $x_{i}^{t+1}$ moves with series steps of Gaussian walks, which can be described as follows:

$$
\begin{aligned}
& x_{i}^{t+1}=x_{i}^{t}+\varepsilon_{1}+\left[\varepsilon_{2} \times \text { best } t_{g}^{t}-\varepsilon_{3} \times x_{i}^{t}\right] \\
& \forall i \in\left\{1,2, \ldots, n_{G}\right\}
\end{aligned}
$$

$\varepsilon_{1} \sim \operatorname{random}(\operatorname{size}(d)) \oplus N\left(\right.$ best $_{g}^{t}, \frac{\log t}{t} \times\left(x_{i}^{t}-\right.$ best $\left.\left._{g}^{t}\right)\right)$

Where, $\varepsilon_{1}$ is a random number generated from Gaussian distribution, $\varepsilon_{2}$ and $\varepsilon_{3}$ are random samples drawn from a uniform distribution within the interval $[0,1]$. best $_{\mathrm{g}}$ is the global best solution (moonlight) obtained in the transverse orientation phase. Based on many optimization algorithms, there is a memory to transfer information from the current generation to the next generation. However, the moths may fall into the fire in the real world due to the lack of an evolutionary memory. This is due to the performance of moths is intensely affected by the short-term memory and the associative learning between the moths. Therefore, the second part of onlooker moths $\mathrm{n}_{\mathrm{A}}=\mathrm{n}_{\mathrm{o}}-\mathrm{n}_{\mathrm{G}}$ will sweep toward the moon light using associative learning immediate memory (ALIM) to imitate the actual behavior of moths in nature. The instantaneous memory is initialized from the continuous uniform of Gaussian distribution on the range from $x_{i}^{\min }-x_{i}^{t}$ to $x_{i}^{\max }-x_{i}^{t}$. The updating equation of this type can be completed in form:

$$
\begin{aligned}
& x_{i}^{t+1}=x_{i}^{t}+0.001 \cdot G\left[x_{i}^{t}-x_{i}^{\min }, x_{i}^{\max }-x_{i}^{t}\right]+\left(1-\frac{g}{G}\right) \cdot r_{1} \\
& .\left(\text { best }_{p}^{t}-x_{i}^{t}\right)+2 g / G \cdot r_{2} \cdot\left(\text { best }_{g}^{t}-x_{i}^{t}\right) \quad \forall i \in\left\{1,2, \ldots, n_{A}\right\}
\end{aligned}
$$

where, $r_{1}$ and $r_{2}$ are random number within the interval $[0,1]$, $2 \mathrm{~g} / \mathrm{G}$ is the social factor, $1-\mathrm{g} / \mathrm{G}$ is the cognitive factor and best $_{\mathrm{p}}$ is a light source selected from the modified swarm based on the probability $p_{i}$.

\section{Implementation of GMSA}

The pseudo code of the proposed GMSA is presented in Table 1. In addition, Fig. 3 explains the step procedure of GMSA to solve the DG and capacitors allocation problems.

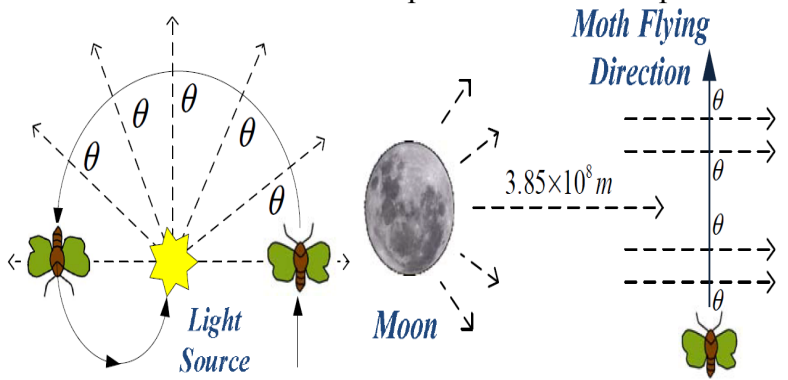

Fig. 2. Orientation behaviour of moth swarm [30]. (a) Moth flying in a spiral path into the nearby light source. (b) Moth flying at a fixed angle relative to moonlight.

Table 1 pseudo code the proposed GMSA

Initialize the moth-swarm population.

Calculate the swarm finesses

Identify the type of each moth:

The worst half of swarm is offsprings(genetic pathfinders) the rest are parents (prospectors and onlookers)

while $t<$ Max number of iterations $T$

for each offspring,

Select two parents based on $p d f$

Identify the crossover points at random

Construct a new offspring by appling GA-crossover on

parent

Mutate the new offspring with the proposed mutation rate

Calculate the probability values $P$.

Select the artificial light sources

End of reconnaissance.

for each prospector moth(best group),

Update the position of prospector moth.

Calculate the fitness of prospector.

End of Transverse orientation.

Define the new moonlight.

for each onlooker moth,

Update the position according to its type.

if $\left(i \in n_{G}\right)$,

Generate Gaussian walk steps $\varepsilon_{1}, \varepsilon_{2}$, and $\varepsilon_{3}$

Move the onlooker position with Gaussian walks $x_{i}^{t+1}$

Else,

Drift the onlooker moth using the associative learning operators and immediate memory.

End if.

Calculate the fitness of onlooker moth.

End of Celestial navigation.

End while.

Print global best solution (moonlight) 


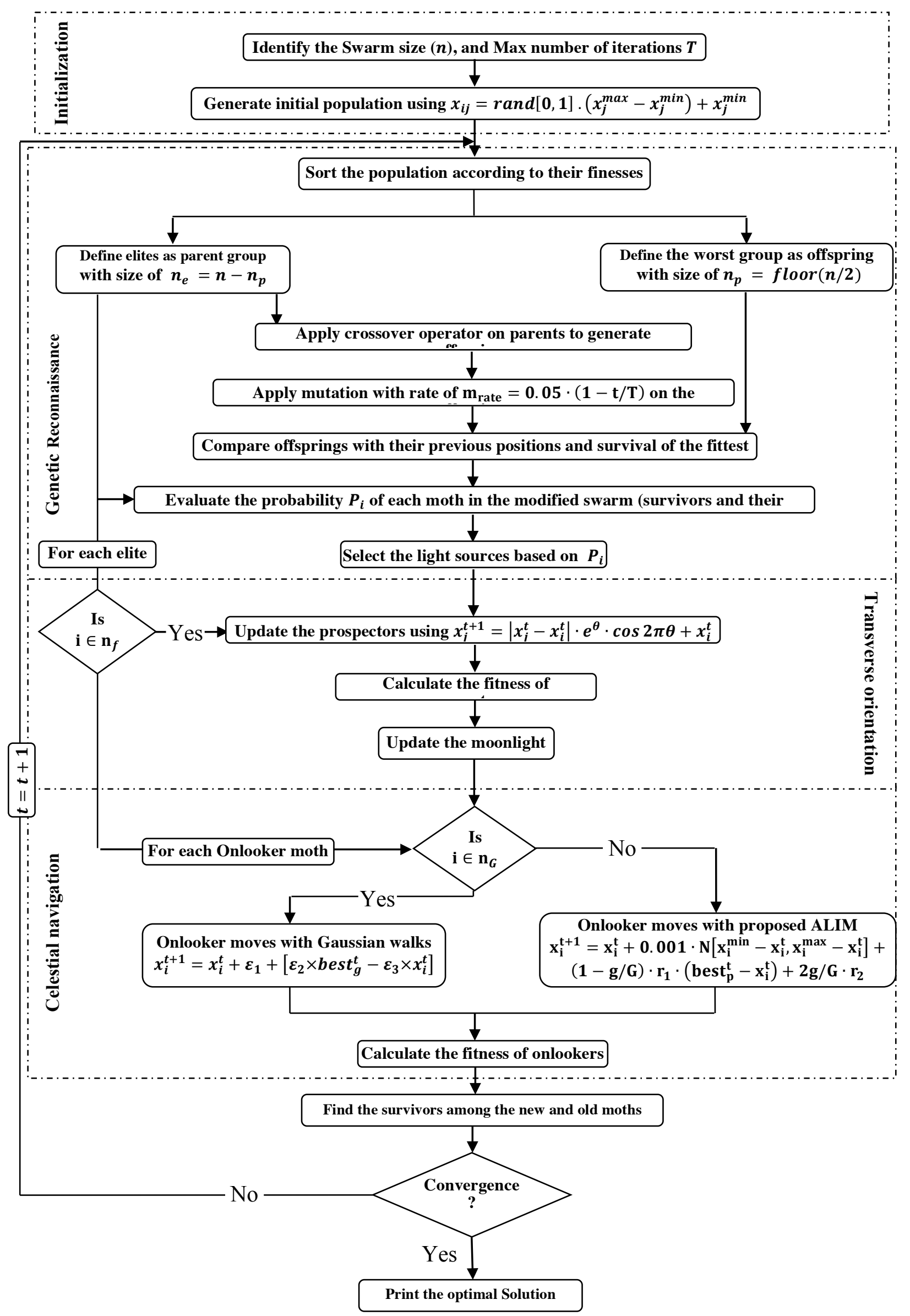

Fig. 3 Flowchart of GMSA 


\section{Results and Discussion}

To evaluate the efficiency of the proposed GMSA method, MSA, GA, FPA and sine-cosine algorithm (SCA) against power loss minimization. The IEEE distribution systems of 33 and 69-bus have been applied for this simulation. The MATLAB 8.6 ® is used to implement the GMSA technique for the optimal DG and capacitor placement problem individually and simultaneously. The test cases taken into consideration are:

Case 1: Optimal shunt capacitors locations and sizing

Case 2: Optimal DG locations and sizing

Case 3: Optimal locations and sizing of DG and shunt capacitors simultaneously

The DG unit is considered as negative $P$ load with real power injection capability. The status of location and rating of DG unit and shunt capacitors are taken as the decision variables. The maximum penetration limit of DG unit is limited to $40 \%$ of the total system real power demand.

\subsection{IEEE 33-Bus Test System}

To evaluate the impact of the proposed hybrid GMSA on the medium network of the RDN, the IEEE 33-bus system has been tested. Fig. 4 shows the single line diagram of this system. The system rated voltage is $12.66 \mathrm{kV}$ with 100 MVA base. The load and line data are given in [17]. Load flow calculation is run before compensation, the minimum bus voltage is registered as 0.9036 p.u at node 18 and the total active power loss at nominal load is $210.98 \mathrm{~kW}$. In the first case, optimal places results of shunt capacitors after 40 independent runs using GMSA, MSA, GA, FPA and SCA under the same conditions are summarized in Table 2.

For this case, the GMSA and GA produce better solutions compared to the MSA and FPA methods, whereas the best power loss value obtained by SCA is much more than the rest of algorithms. Using the proposed GMSA method, the real power loss is diminished to $137.21 \mathrm{~kW}$ as
$34.96 \%$ of the base case. It is considered the lowest value compared to the other methods.

In addition, the system voltage profile is improved and the worst bus voltage is enhanced to $0.9343 \mathrm{p}$.u as shown in Fig. 5(a). In terms of the convergence features, the GMSA and GA have a speedy and smooth rate of convergence more than the other algorithms, as shown in Fig. 5(b) for power losses. In case of using only DGs, the hybrid GMSA method still has the preference in reducing the power loss which is minimized to $67.97 \mathrm{~kW}$ comparing with GA and MSA for $70.46 \mathrm{~kW}$ and $71.34 \mathrm{~kW}$, respectively as seen in Table 3 , whereas FPA and SCA indicated a severe changes along the search process, which leads to unstable final solution as shown in Fig. 6(b). Moreover, Fig. 6(a) confirms the effectivity of the proposed technique by showing the improvement in system voltages. Case 3 proved the effectiveness of the proposed hybrid method as it directed quickly towards its optimal value of power loss to $7.94 \mathrm{~kW}$ with highest convergence speed compared to GA, MSA, FPA and SCA as tabulated in Table 4 and depicted in Fig. 7(b). In addition, it is obvious from Fig. 7(a) that the best minimum bus voltage is enhanced to 0.9938 p.u with GMSA It can be seen from Fig. 8 that the proposed hybrid algorithm provides a significant improvement of bus voltage profile with case- 3 as compared with other cases. The results stated that the GMSA method performed better than the other algorithms over all cases of IEEE 33-bus system.

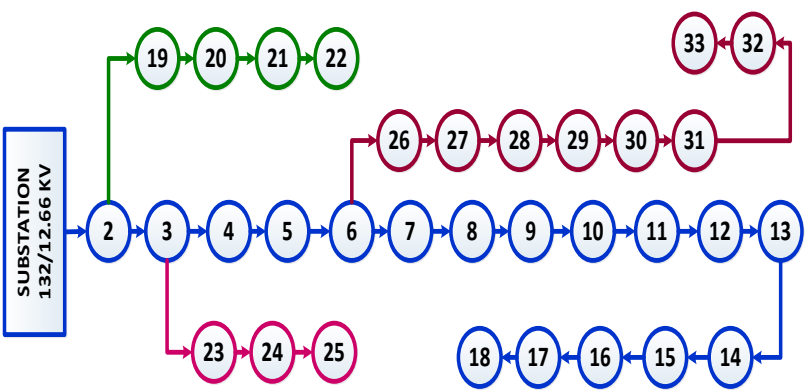

Fig. 4. Single line diagram of IEEE 33-bus RDN [17]

Table 2. Case 1(Cap. only) Comparison results of different optimization techniques (33-bus system)

\begin{tabular}{cccccc}
\hline Techniques & $\mathrm{V}_{\min }(\mathrm{p} . \mathrm{u})$ & $\begin{array}{c}\mathrm{V}_{\max } \\
(\mathrm{p} . \mathrm{u})^{*}\end{array}$ & $\begin{array}{c}\text { Optimal CAP location (bus no. }) \\
\text { Optimal size (KVAR) }\end{array}$ & $\begin{array}{c}\mathrm{P}_{\text {loss }}(\mathrm{KW}) \\
\text { reduction }\end{array}$ \\
\hline Base Case & 0.9036 & 0.9971 & - & 210.98 & - \\
\hline Proposed GMSA & 0.9343 & 0.9979 & $2(150), 12(450), 18(900), 24(450), 30(1050)$ & 137.21 & 34.96 \\
\hline GA & 0.9329 & 0.9977 & $2(150), 3(750), 2(450), 13(350), 18(1200)$ & 138.1 & 34.54 \\
\hline MSA & 0.9297 & 0.9975 & $2(150), 6(750), 8(750), 13(1050), 24(1050)$ & 139.91 & 33.68 \\
\hline FPA & 0.9254 & 0.9975 & $8(300), 14(450), 19(750), 30(1050)$ & 141.82 & 32.78 \\
\hline SCA & 0.9236 & 0.9974 & $8(750), 12(750), 13(1500), 24(600), 30(1050)$ & 144.83 & 31.35 \\
\hline SA [24] & 0.9591 & NA & $10(450), 14(900), 30(350)$ & 151.75 & 28.07 \\
\hline FRCGA [31] & \multirow{2}{*}{ NA } & NA & $28(25), 6(475), 29(300), 8(175), 30(400)$, & 141.24 & $3(350)$ \\
\hline
\end{tabular}

Table 3. Case 2 (DG only) Comparison results of different optimization techniques (33-bus system)

\begin{tabular}{|c|c|c|c|c|c|}
\hline Techniques & $\mathrm{V}_{\min }(\mathrm{p} . \mathrm{u})$ & $\mathrm{V}_{\max }(\mathrm{p} . \mathrm{u})$ & $\begin{array}{l}\text { Optimal DG location (bus no.) Optimal size } \\
(\mathrm{Kw})\end{array}$ & $\mathrm{P}_{\text {loss }}(\mathrm{KW})$ & $\begin{array}{l}\% \text { Loss } \\
\text { reduction }\end{array}$ \\
\hline Base Case & 0.9036 & 0.9971 & - & 210.98 & - \\
\hline Proposed GMSA & 0.9725 & 0.9988 & $\begin{array}{c}29(445.4), 10(399.1), 15(439.4), 25(495.3), \\
26(495.3), 32(461.8)\end{array}$ & 67.97 & 67.78 \\
\hline GA & 0.9648 & 0.9986 & $\begin{array}{clll}26(487.3) & 29(426.4) & 25(481.3) & 12(487.3) \\
& 32(487.3) & 17(156.1) & \\
\end{array}$ & 70.46 & 66.6 \\
\hline MSA & 0.9587 & 0.9986 & $\begin{array}{c}24(386.5), 25(495.3), 27(495.3), 33(495.3), \\
15(495.3), 29(296)\end{array}$ & 71.34 & 66.19 \\
\hline
\end{tabular}




\begin{tabular}{|c|c|c|c|c|c|}
\hline FPA & 0.9647 & 0.9985 & $\begin{array}{c}33(495.3), 25(323.3), 13(470.8) \\
9(434.9), 7(233.5)\end{array}$ & 73.01 & 65.39 \\
\hline SCA & 0.9561 & 0.9984 & $\begin{array}{c}\text { 14(495.3), 31(495.3), 24(425.4), } 8(484.6) \\
4(390.9)\end{array}$ & 77.92 & 63.07 \\
\hline
\end{tabular}

Table 4. Case 3 (CAP \& DG) Comparison results of different optimization techniques (33-bus system)

\begin{tabular}{ccccccc}
\hline Techniques & $\begin{array}{c}\mathrm{V}_{\min } \\
(\mathrm{p} . \mathrm{u})\end{array}$ & $\begin{array}{c}\mathrm{V}_{\max } \\
(\mathrm{p} . \mathrm{u})\end{array}$ & $\begin{array}{c}\text { Optimal CAP location (bus no.) } \\
\text { Optimal size (KVAR) }\end{array}$ & $\begin{array}{c}\text { Optimal DG location (bus no.) } \\
\text { Optimal size (Kw) }\end{array}$ & $\begin{array}{c}\mathrm{P}_{\text {loss }} \\
(\mathrm{KW})\end{array}$ & $\begin{array}{c}\% \text { Loss } \\
\text { reduction }\end{array}$ \\
\hline Base Case & 0.9036 & 0.9971 & -1210.98 & - \\
\hline $\begin{array}{c}\text { Proposed } \\
\text { GMSA }\end{array}$ & 0.9938 & 1.001 & $\begin{array}{c}30(600), 11(350), 31(450), \\
14(150)\end{array}$ & $\begin{array}{c}24(418.2), 28(474.8), 32(478.6), \\
11(448.7)\end{array}$ & 7.94 & 96.24 \\
\hline GA & 0.9862 & 0.9993 & $12(450), 33(750), 6(450)$ & $8(493.7), 14(495.3), 25(495.3)$ & 16.41 & 92.22 \\
\hline MSA & 0.9786 & 0.9989 & $30(1050), 16(450)$ & $\begin{array}{c}25(155.3), 11(455.4), 28(455.3), \\
31(326.9)\end{array}$ & 24.87 & 88.21 \\
\hline FPA & 0.9829 & 0.9995 & $\begin{array}{c}33(150), 10(150), 32(600), \\
4(1050)\end{array}$ & $\begin{array}{c}24(93.7), 8(421.2), 23(226.6), \\
28(495.3)\end{array}$ & 29.39 & 86.08 \\
\hline SCA & 0.9739 & 0.9985 & $\begin{array}{c}2(150), 4(350), 25(350), \\
30(1200)\end{array}$ & $\begin{array}{c}10(285.7), 17(176.4), 33(470.4), \\
18(381.8)\end{array}$ & 40.55 & 80.78 \\
\hline
\end{tabular}
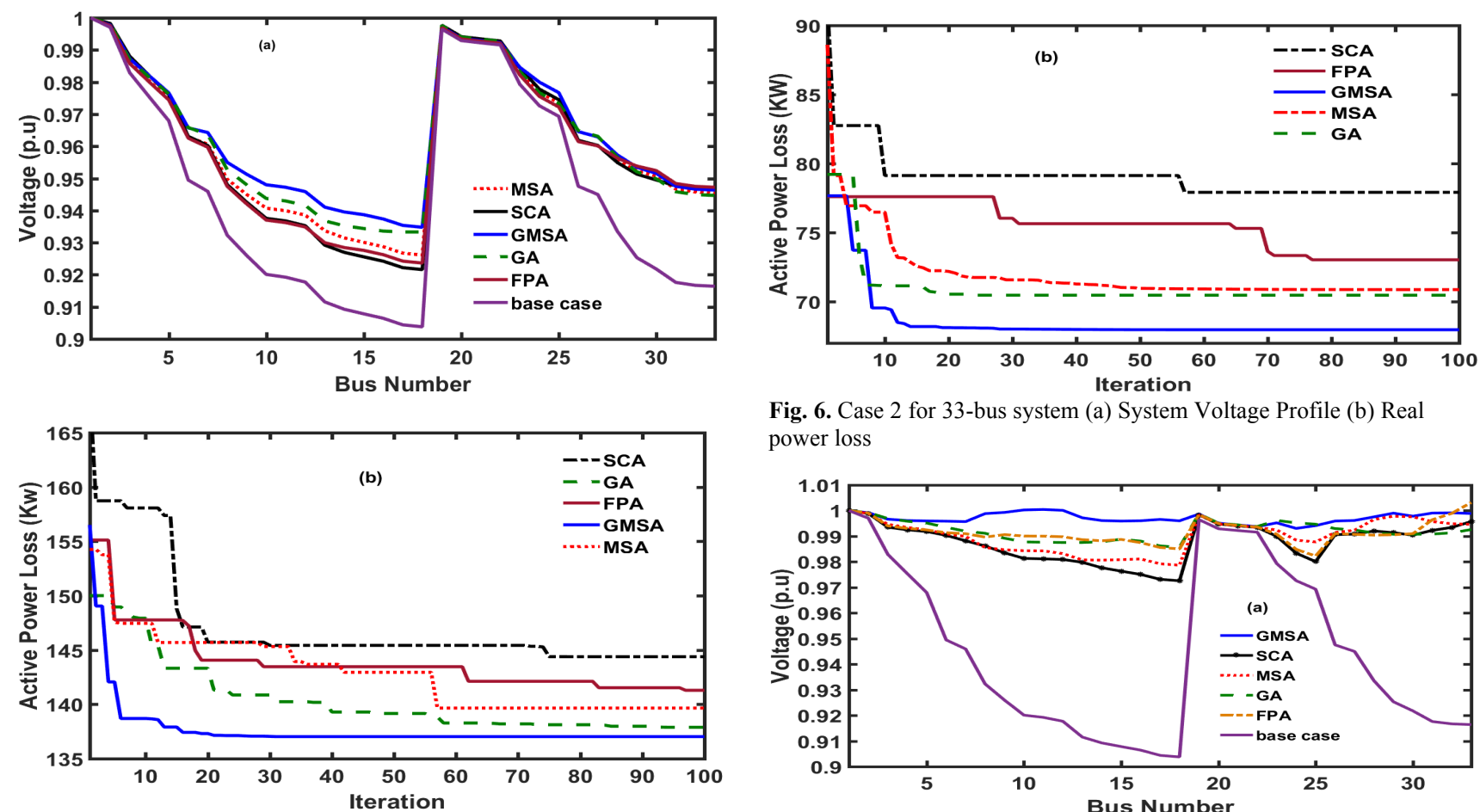

Fig. 6. Case 2 for 33-bus system (a) System Voltage Profile (b) Real power loss

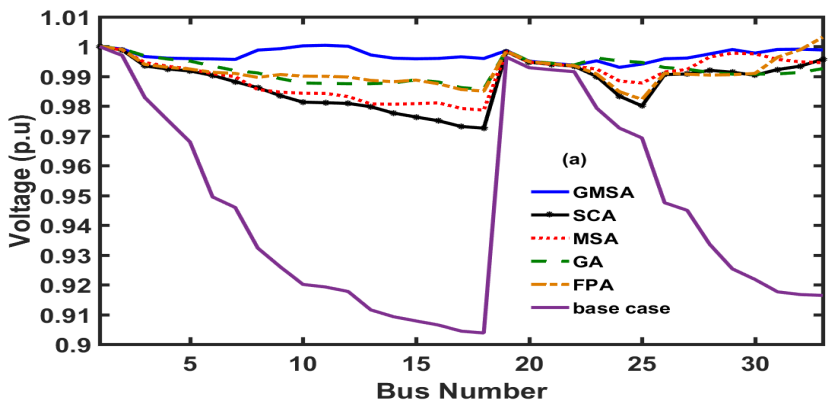

Fig. 5. Case 1 for 33-bus system (a) System Voltage Profile (b) Real power loss
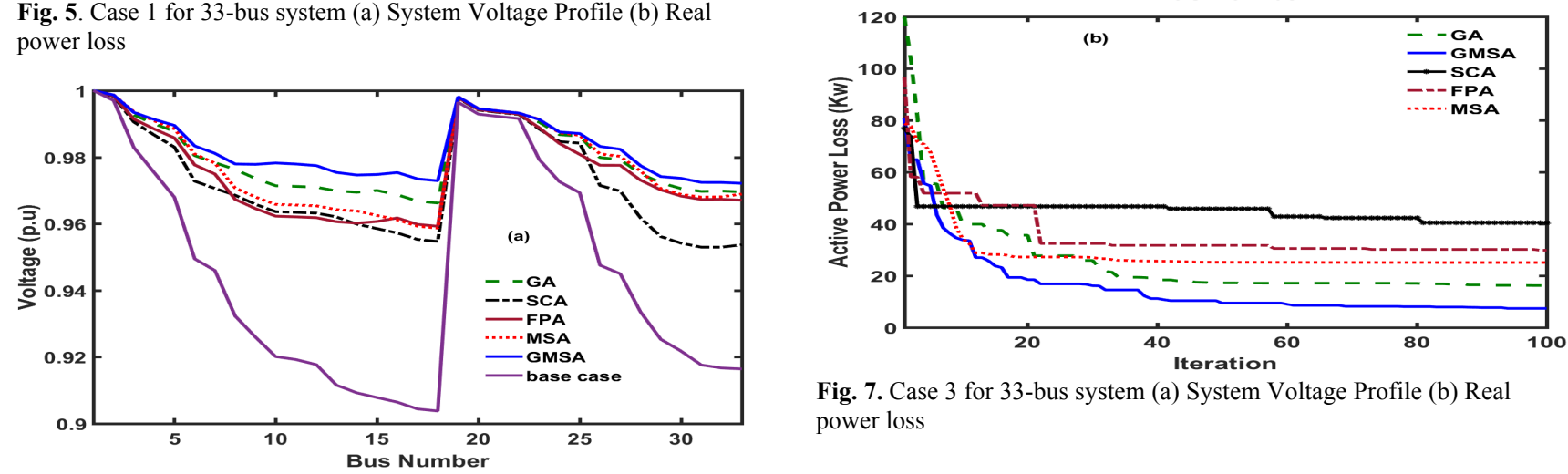

Fig. 7. Case 3 for 33-bus system (a) System Voltage Profile (b) Real power loss 


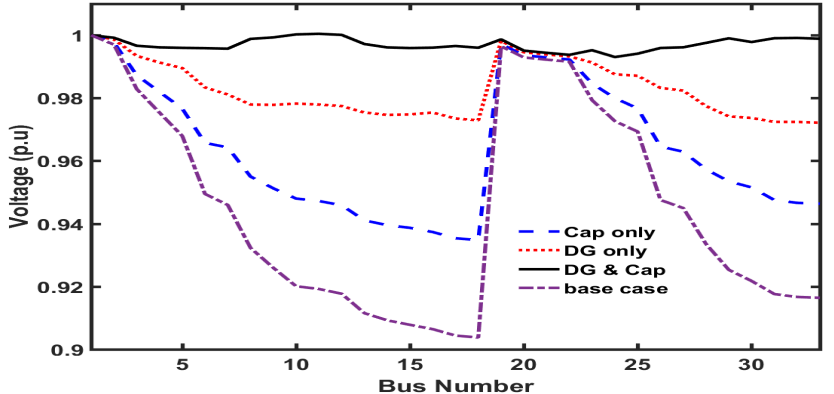

Fig. 8. Voltage Profile for 33-bus system with GMSA

\subsection{IEEE 69-Bus Test System}

To investigate the effectiveness of the proposed GMSA on a large scale of RDN, it is applied on the IEEE 69-bus system, which consists of 69 buses and 68 branches as shown in Fig. 9. This system is operated with 100 MVA base, $12.66 \mathrm{kV}$ rated voltage, and total system load is (1.896MW+j1.347MVAR). All data of lines and loads are given in [17]. The total real power loss for the base case without using capacitors or DGs is found at $224.975 \mathrm{~kW}$ with the lowest bus voltage at bus 65 is 0.9092 p.u. In case1, using the capacitors banks alone helps in reducing the system power loss by $35.98 \%$ from the base case using the GMSA with quickly convergence rate better than MSA, FPA and SCA, whereas the GA has the second best final solution after GMSA with more convergence rate as depicted in Fig. 10(b). Furthermore, the lowest bus voltage is increased from 0.9092 PU to 0.9331 p.u as seen in Fig. 10(a) which indicates the difference between the system voltages profile before and after compensation with the capacitors banks using the same algorithms under the same conditions. All simulation results obtained with the proposed hybrid algorithm and other methods for cases 1-3 are summarized in Table 5. In case 2 of using DGs only, GMSA gave a good performance as it directed to its optimal power loss value very faster than other techniques as shown in Fig.11 (b). The power loss is decreased to $67.79 \mathrm{~kW}$ with increase the minimum bus voltage to 0.9819 p.u as depicted in Fig. 11(a). The GA and MSA came in the second best solutions for reducing the power loss to acceptable values. But, the FPA and SCA indicated severe variations along the optimization process, which leads to an unstable final solution. In order to evaluate the robustness of the proposed paradigm, a full comparison in terms of best, power loss and minimum voltage is given in Table 6 .

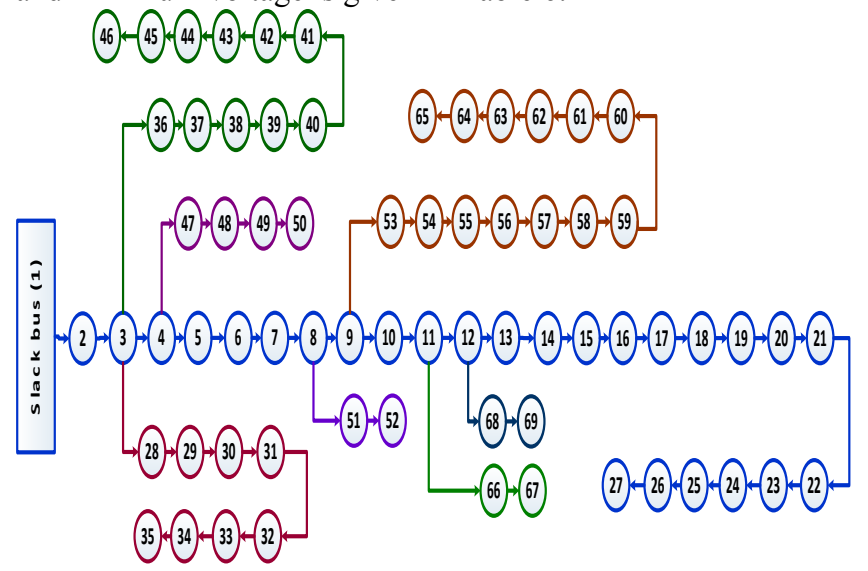

Fig. 9. Single line diagram of IEEE 69-bus RDN [17]
GMSA investigated the best performance with case 3. It reduced the power loss to $5.093 \mathrm{~kW}$ with $97.7 \%$ loss reduction compared to $16.72 \mathrm{~kW}$ with GA, which is considered the second algorithm in reducing the power loss. In contrast, MSA, FPA and SCS still suffer from excessively slow convergence as shown in Fig. 12(b). Furthermore, the minimum bus voltage increased to a very good value (0.9976 p.u) during this case using the GMSA compared to other methods as depicted in Fig. 12(a). Table 7 summarizes all simulation results of this case such as optimal capacitors/DGs locations, total active power loss, minimum voltage, maximum voltage and loss reduction. Also, it can be noted from Fig. 13 that the proposed hybrid GMSA provides a significant enhancement of voltage profile with case- 3 as compared with cases 1 and 2. Results indicated that the proposed GMSA minimized the objective function, and provided remarkable results compared to other proposed algorithms and those reported in the literature.
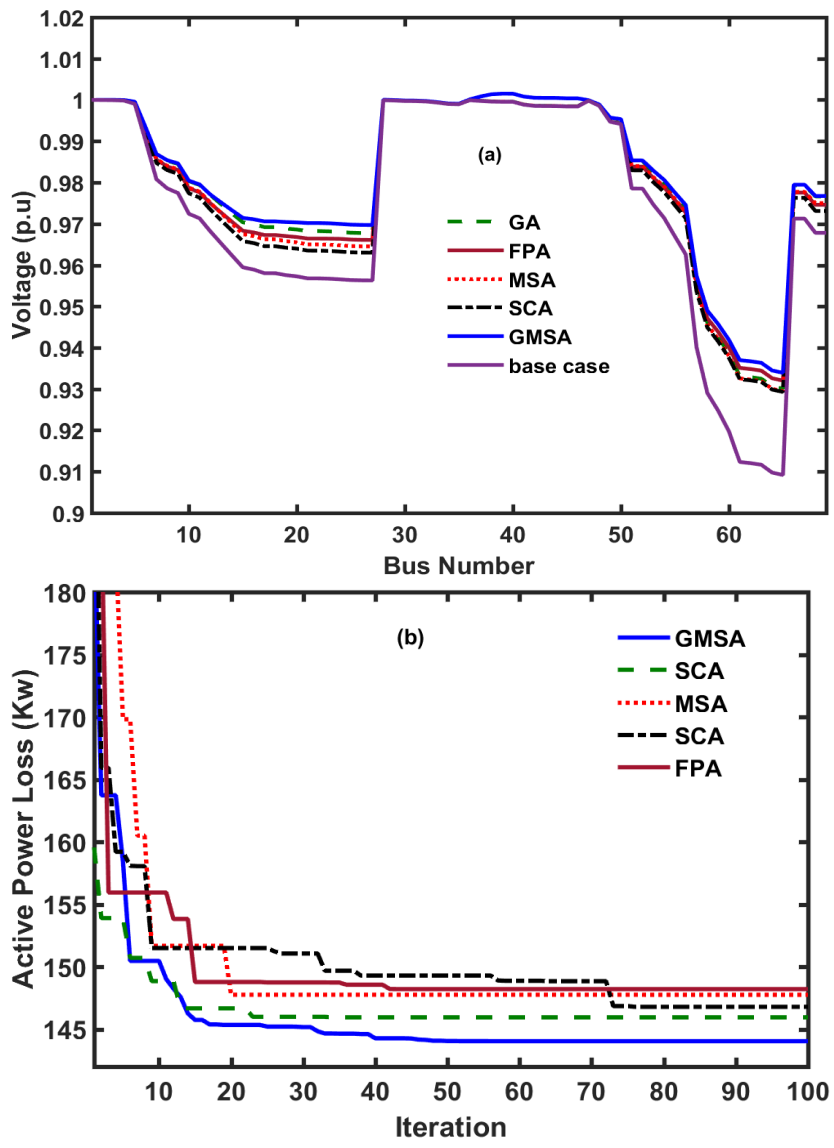

Fig. 10. Case 1 for 69-bus system (a) System Voltage Profile (b) Real power loss 
Table 5. Case 1(Cap. only) Comparison results of different optimization techniques (69-bus system)

\begin{tabular}{cccccc}
\hline Techniques & $\mathrm{V}_{\min }(\mathrm{p} . \mathrm{u})$ & $\mathrm{V}_{\max }(\mathrm{p} . \mathrm{u})$ & $\begin{array}{c}\text { Optimal location (bus no.) } \\
\text { Optimal size (KVAR) }\end{array}$ & $\begin{array}{c}\mathrm{P}_{\text {loss }} \\
(\mathrm{KW})\end{array}$ & $\begin{array}{c}\text { \% Loss } \\
\text { reduction }\end{array}$ \\
\hline Base Case & 0.9092 & 0.9999 & - & 224.98 & - \\
\hline $\begin{array}{c}\text { Proposed } \\
\text { GMSA }\end{array}$ & 0.9331 & 0.9999 & $2(750), 12(300), 50(450), 61(900), 64(350)$ & 144.03 & 35.98 \\
\hline GA & 0.9312 & 0.9999 & $12(600), 28(150), 50(450), 63(350), 62(900)$ & 146.69 & 34.79 \\
\hline MSA & 0.9305 & 1.000 & $\begin{array}{c}37(150), 36(1050) 47(150) \\
26(150) 10(900) 61(1050)\end{array}$ & 147.98 & 34.23 \\
\hline FPA & 0.9321 & 1.000 & $\begin{array}{c}62(1350), 2(2100), 20(1500), 45(1950), 69(450), \\
54(750), 48(750), 6(150)\end{array}$ & 148.25 & 34.1 \\
\hline SCA & 0.9294 & 0.9999 & $\begin{array}{c}50(1050), 2(750), 2(1950), 61(1500), 62(300), \\
12(300), 10(600), 28(450)\end{array}$ & 146.98 & 34.66 \\
\hline
\end{tabular}
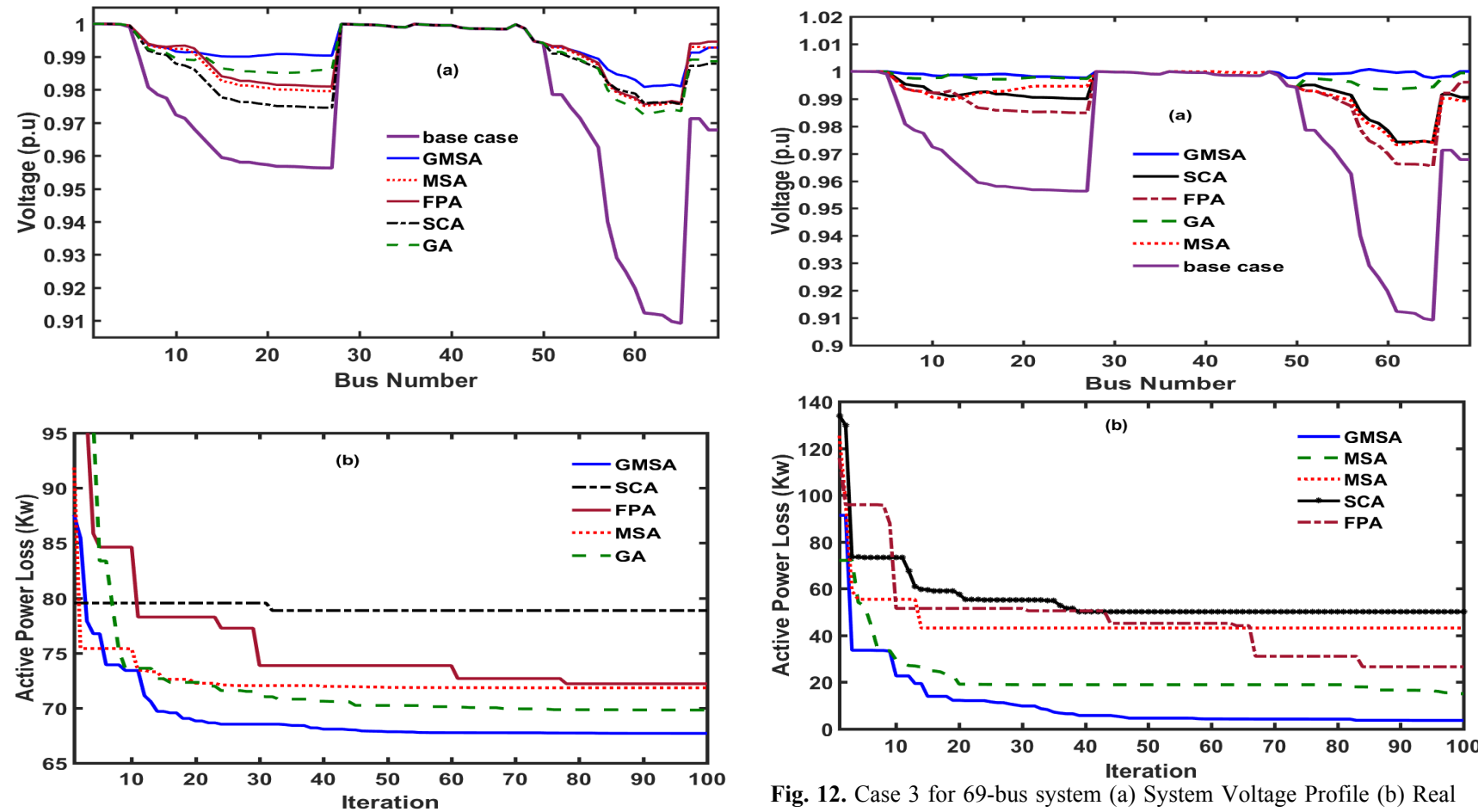

Fig. 11. Case 2 for 69-bus system (a) System Voltage Profile (b) Real

Fig. 12. Case 3 for 69-bus system (a) System Voltage Profile (b) Real power loss power loss

Table 6. Case 2 (DG only) Comparison results of different optimization techniques (69-bus system)

\begin{tabular}{|c|c|c|c|c|c|}
\hline Techniques & $\begin{array}{l}V_{\min } \\
\text { (p.u) }\end{array}$ & $\begin{array}{l}V_{\max } \\
\text { (p.u) }\end{array}$ & $\begin{array}{l}\text { Optimal location (bus no.) } \\
\text { Optimal size (Kw) }\end{array}$ & $\begin{array}{c}\mathbf{P}_{\text {loss }} \\
(\mathbf{K W})\end{array}$ & $\begin{array}{l}\% \text { Loss } \\
\text { reduction }\end{array}$ \\
\hline Base Case & 0.9092 & 0.9999 & - & 224.98 & - \\
\hline $\begin{array}{l}\text { Proposed } \\
\text { GMSA }\end{array}$ & 0.9819 & 0.9999 & $\begin{array}{c}53(359.8), 67(282.2), 42(100.1), 62(281.07), \\
60(307.04)\end{array}$ & 67.79 & 69.87 \\
\hline GA & 0.9736 & 0.9999 & $\begin{array}{c}\text { 62(504.1), 68(350.2), 64(497.2), 57(300.2), } \\
61(503.6)\end{array}$ & 70.15 & 68.81 \\
\hline MSA & 0.9741 & 0.9999 & $\begin{array}{c}\text { 69(424.6), 62(497.1), 64(506.7), 61(506.8), } \\
19(382.1)\end{array}$ & 72.1 & 67.95 \\
\hline FPA & 0.9774 & 1.0000 & $\begin{array}{c}63(506.8), 42(388.3), 62(500.36), 58(285.5), \\
15(42.04) 64(365.6)\end{array}$ & 72.32 & 67.85 \\
\hline SCA & 0.9748 & 0.9999 & $62(446.8), 7(152.6), 2(140.9), 60(396.2), 64(506.8)$ & 78.86 & 64.95 \\
\hline
\end{tabular}

Table 7. Case 3 (CAP \& DG) Comparison results of different optimization techniques (69-bus system)

\begin{tabular}{ccccccc}
\hline Techniques & $\begin{array}{c}\mathbf{V}_{\min } \\
(\mathbf{p . u})\end{array}$ & $\begin{array}{c}\mathbf{V}_{\max } \\
(\mathbf{p . u})\end{array}$ & $\begin{array}{c}\text { Optimal CAP location (bus } \\
\text { no.) Optimal size (KVAR) }\end{array}$ & $\begin{array}{c}\text { Optimal DG location (bus no.) } \\
\text { Optimal size (Kw) }\end{array}$ & $\begin{array}{c}\mathbf{P}_{\text {loss }} \\
(\mathbf{K W})\end{array}$ & $\begin{array}{c}\% \text { Loss } \\
\text { reduction }\end{array}$ \\
\hline Base Case & 0.9092 & 0.9999 & & & 224.98 & - \\
\hline $\begin{array}{c}\text { Proposed } \\
\text { GMSA }\end{array}$ & 0.9976 & 1.000 & $\begin{array}{c}50(450), 48(150), 61(450), \\
\text { 23(1200), 10(150) }\end{array}$ & $\begin{array}{c}69(346.5), 18(383.2), 62(446.4), \\
58(360.7)\end{array}$ & 5.093 & 97.7 \\
\hline GA & 0.9943 & 0.9999 & $69(150), 2(1350), 24(450)$, & $58(318.4), 22(398.4), 36(137.4)$, & 16.72 & 92.57 \\
\hline \multicolumn{7}{c}{63} \\
\end{tabular}




\begin{tabular}{|c|c|c|c|c|c|c|}
\hline & & & $19(150), 63(1350)$ & $64(506.6), 60(449.8)$ & & \\
\hline MSA & 0.9726 & 1.000 & $\begin{array}{c}49(150), 2(150), 69(150) \\
62(1200)\end{array}$ & $\begin{array}{c}46(34.2), 27(506.8), 58(486.1) \\
19(506.8), 65(506.8)\end{array}$ & 43.61 & 80.62 \\
\hline FPA & 0.9657 & 1.000 & $\begin{array}{c}\text { 31(150), 2(2100), 3(1200), } \\
39(1050), 62(750)\end{array}$ & $\begin{array}{c}68(253.8), 26(506.8), 43(310.9) \\
57(20.5), 52(336.3)\end{array}$ & 26.59 & 88.18 \\
\hline SCA & 0.9752 & 1.000 & $\begin{array}{c}2(150), 55(150), 59(1050), \\
26(350), 32(150)\end{array}$ & $65(454.4), 17(253.4), 61(350.6)$ & 50.12 & 77.72 \\
\hline
\end{tabular}

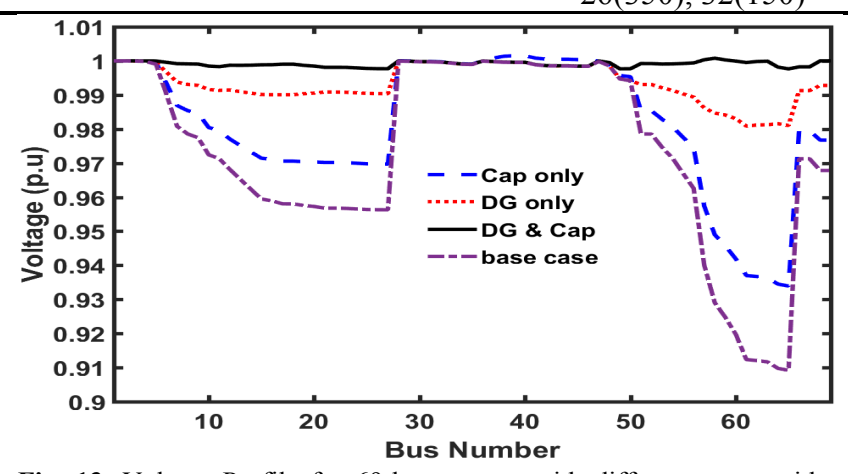

Fig. 13. Voltage Profile for 69-bus system with different cases with GMSA

\section{Conclusion}

In this article, the exploitation ability of the GMSA has been maintained by using the best moths in the swarm to perform that role in the phases of the transverse orientation and celestial navigation. The tradeoff between the global and local search has been regulated by introducing an adaptive mutation operation of GA on the pathfinders as the largest population group in the swarm. In addition, individuals have been cooperated to produce the light sources for guidance of the transverse orientation phase, which assists the exploration ability in such exploitation phase and enhance the solution diversity. The complexity of reconnaissance phase has been reduced.
GMSA approach and four heuristic search algorithms, GA, MSA, FPA and SCA have been successfully applied to the medium and large-scale electrical distribution systems networks (IEEE 33, 69-bus systems) to solve the problem of capacitors or/and distributed generation (DGs) placement and ratings for minimizing the total real power losses. The proposed GMSA can improve the voltage profile at each bus in these systems. GMSA method presented a desirable and superior performance with stable convergence against the other techniques. Whereas, the GA and MSA have the second best final solution after GMSA in all test cases. On the other hand, FPA and SCA techniques indicated severe changes along the search process, which leads to an unstable final solution. Results stated that the proposed GMSA minimized the objective function, and provided remarkable results compared to other proposed algorithms and those reported in the literature. Hence, the applications of the proposed GMSA method can be considered as the most recent optimization algorithms for the network reconfiguration and deal with the protection coordination system in presence of capacitors banks and distributed generation during grid faults are the future scope of this work.

This is an Open Access article distributed under the terms of the Creative Commons Attribution Licence

\section{References}

1. A. Y. Abdelaziz, Ehab S. Ali \& Sahar M. Abdelazim, "Flower Pollination Algorithm for Optimal Capacitor Placement and Sizing in Distribution Systems" Electrical Power Components and Systems. Issue 5, Volume 44, 2016, pp. 544-555.

2. J.B.V. Subrahmanyam, Optimal capacitor placement in unbalanced radial distribution networks, J. Theor. Appl. Inform. Technol. 6 (1) (2009), pp. 106-115.

3. T.S. Chung, Ge Shaoyun, A recursive LP-based approach for optimal capacitor allocation with cost-benefit consideration, Electric Power Syst. Res. (1997), pp. 129-136.

4. A. A. El-Gaafary et al., "Grey wolf optimization for multi input multi output system", Univers. J. Commun. Network, vol. 3, no. 1, 2015, pp. 1-6.

5. A. A. Mohamed et al., "Multi-objective Modified Grey Wolf Optimizer for Optimal Power Flow", IEEE, 18th International Middle East Power Systems Conference (MEPCON), 2016, pp. 982-990.

6. A. A. Mohamed et al., "Energy management with capacitor placement for economics low carbon emissions using modified multi-objective grey wolf optimizer", 3rd International Conference on Energy Systems and Technologies, 2015, pp.261-270.

7. A. A. Mohamed et al., "Multi-objective states of matter search algorithm for TCSC-based smart controller design", Electr. Power Syst. Res., vol. 140, 2016, pp. 874-885.

8. A. A. Mohamed, "Design static VAR compensator controller using artificial neural network optimized by modify Grey Wolf Optimization", IEEE, International Conference on Neural Networks (IJCNN), 2015, pp. 1-7.
9. Almoataz Y. Abdelaziz, Ehab S. Ali, Sahar M. Abdelazim, "flower pollination algorithm for optimal capacitor placement and sizing in distribution systems", Electrical Power Components Systems, Volume 44, Issue 5, 2016, pp. 544-555,

10. K. Prakash, M. Sydulu, "Particle swarm optimization based capacitor placement on radial distribution system", Proceedings of IEEE Power Engineering Society General Meeting (2007), pp. 1-5.

11. T. Kerdphol, Kiyotaka Fuji, Y. Mitani, M. Watanabe and Yaser Qudaih "Optimization of a battery energy storage system using particle swarm optimization for stand-alone microgrids" Electrical Power and Energy Systems 81, 2016, pp. 32-39.

12. A. Elsheikh, Y. Helmy, Y. Abouelseoud, A. Elsherif, "Optimal capacitor placement and sizing in radial electric power systems", Alexandria Eng J, 53 (4) (2014), pp. 809-816.

13. Sydulu M, Reddy VVK, "Index and GA based optimal location and sizing of distribution system capacitors", IEEE power engineering society general meeting 2007; 24th-28th June, pp. 1-4.

14. Sneha Sultana, Provas Kumar Roy, "Optimal capacitor placement in radial distribution systems using teaching learning-based optimization”, Elsevier Int. J. Electr. Power Energy Syst., 54 (2014), pp. 387-398.

15. R.V. Rao, V.K. Patel, "Optimization of mechanical draft counter flow wet-cooling tower using artificial bee colony algorithm", Energy Convers Manage, 52 (7) (2011), pp. 2611-2622.

16. Attia A. El-Fergany, Almoataz Y. Abdelaziz, "Cuckoo Searchbased Algorithm for Optimal Shunt Capacitors Allocations in Distribution Networks", Electrical Power Components and Systems. Issue 16, Volume 41, 2016, pp. 1567-1581. 
17. Y. Mohamed Shuaiba, M. Surya Kalavathib, C. Christober Asir Rajan, "Optimal capacitor placement in radial distribution system using Gravitational Search Algorithm", International Journal of Electrical Power \& Energy Systems, Volume 64, 2015, PP. 384 397.

18. Felipe G. Duque, Leonardo W. de Oliveira, Edimar J. de Oliveira, André L.M. Marcato, Ivo C. Silva Jr, "Allocation of capacitor banks in distribution systems through a modified monkey search optimization technique", International Journal of Electrical Power \& Energy Systems, Volume 73, 2015, PP. 420-432.

19. D.B. Prakash, C. Lakshminarayana, "Optimal siting of capacitors in radial distribution network using Whale Optimization Algorithm", Alexandria Eng J. (2016) http://dx.doi.org/10.1016/j.aej.2016.10.002.

20. E.S. Alia, S.M. Abd Elazima, A.Y. Abdelaziz, "Improved Harmony Algorithm for optimal locations and sizing of capacitors in radial distribution systems", International Journal of Electrical Power \& Energy Systems 79 (2016), pp. 275-284.

21. Emad A. Mohamed, Al-Attar A. Mohamed, T. Kerdphol, Y. Mitani, " Optimization of reactive compensation in distribution networks based on moth swarm intelligence for multi-load levels", International Review of Electrical Engineering, Vol 12, No 4, 2017.

22. M. Ramalinga Rajua, K.V.S. Ramachandra Murthy, K. Ravindran, "Direct search algorithm for capacitive compensation in radial distribution systems", International Journal of Electrical Power \& Energy Systems, Volume 42, Issue 1, 2012, PP. 24-30.

23. S. Neelima, P.S. Subramanyam, "Optimal capacitor placement in distribution networks for loss reduction using differential evolution incorporating dimension reducing load flow for different load levels", Energytech, 2012.

24. H.D. Chiang, J.C. Wang, O. Cockings, H.D. Shin, "Optimal capacitor placements in distribution systems: part 1: a new

\section{Nomenclature}

$P_{k} \quad$ Real power flow from bus $\mathrm{k}$

$Q_{k} \quad$ Reactive power flow from bus k

$P_{L k} \quad$ Real power load connected at bus k

$Q_{L k} \quad$ Reactive power load connected at bus k

$P_{L(k+} \quad$ Real power load connected at bus k +1

${ }^{l)}{ }_{L(k+} \quad$ Reactive power load connected at bus $\mathrm{k}+1$

1)

$R_{k} \quad$ Resistance connected between buses $\mathrm{k}$ and $\mathrm{k}+1$

$X_{k} \quad$ Reactance connected between buses $\mathrm{k}$ and $\mathrm{k}+1$

$V_{k} \quad$ Voltage at bus $\mathrm{k}$

$V_{k+1} \quad$ Voltage at bus $\mathrm{k}+1$

$P_{s v s} \quad$ Network active power

$P_{D G} \quad$ Active power of DG

$P_{d} \quad$ Active power demand

$Q_{f c} \quad$ Reactive power compensation

$V_{\min } \quad$ Minimum bus voltage value

$V_{\max } \quad$ Maximum bus voltage value

$P_{\text {Tloss }} \quad$ Tap setting of transformer

$n_{p} \quad$ Number of pathfinders moths

$\mu^{t} \quad$ Variation coefficient

$\sigma_{j}^{t} \quad$ Dispersal degree

best $_{g}$ The global best solution

$\varepsilon_{l} \quad$ Random samples drawn from Gaussian stochastic distribution

$\varepsilon_{2}, \varepsilon_{3} \quad$ Random numbers distributed uniformly within interval $[0,1]$

$r_{1}, r_{2} \quad$ Random number within the interval $[0,1]$

$Q_{s y s} \quad$ Network reactive power

$Q_{D G} \quad$ Reactive power of DG

$Q_{d} \quad$ Reactive power demand formulation and the overall problem", IEEE Trans. Power Deliv, 5 (2) (1990), pp. 634-642.

25. R. Srinivasan Rao, S.V.L. Narasimham, M. Ramalinga Raju, "Optimal capacitor placement in a radial distribution system using Plant Growth Simulation Algorithm", International Journal of Electrical Power \& Energy Systems, Volume 33, Issue 5, 2011, pp. $1133-1139$.

26. Ching-Tzong Su, Guor-Rung Lii, Chih-Cheng Tsai, "Optimal capacitor allocation using fuzzy reasoning and genetic algorithms for distribution systems", Mathematical and Computer Modelling, Volume 33, Issues 6-7, 2001, pp. 745-757.

27. Mostafa Sedighizadeh, Marzieh Dakhem, Mohammad Sarvi, Hadi Hosseini Kordkheili, "Optimal reconfiguration and capacitor placement for power loss reduction of a distribution system using improved binary particle swarm optimization", Int J Energy Environ Eng. (2014) 5: 73. Doi: 10.1007/s40095-014-0073-9.

28. Ying-Tung Hsiao, Chia-Hong Chen, "Optimal capacitor placement in distribution systems using a combination fuzzy-GA method", International Journal of Electrical Power \& Energy Systems, Volume 26, Issue 7, 2004, pp. 501-508.

29. J. A. Micheline Ruba and S. Ganesh "Power Flow Analysis for Radial Distribution Systems using Backward/Forward Sweep Method" Vol 8, No.10, 2014, pp. 1621 - 1625.

30. Al-Attar Ali Mohamed, Yahia S. Mohamed, Ahmed A.M. ElGaafaryb, Ashraf M. Hemeida, "Optimal power flow using moth swarm algorithm”, Electric Power Systems Research, Volume 142, 2017, pp. 190-206.

31. Ahmed R. Abul'Wafa, "Optimal capacitor placement for enhancing voltage stability in distribution systems using analytical algorithm and Fuzzy-Real Coded GA", International Journal of Electrical Power \& Energy Systems, Vol 55, 2014, pp. 246-252. 